Sonsoles Gutiérrez Medina, Teresa Gavela-Pérez, María Nieves Domínguez-Garrido, Elisa Gutiérrez-Moreno, Adela Rovira, Carmen Garcés and Leandro Soriano-Guillén*

\title{
The influence of puberty on vitamin D status in obese children and the possible relation between vitamin $D$ deficiency and insulin resistance
}

\begin{abstract}
Background: Puberty can affect vitamin D levels. Objectives: The goal of this study was to analyze the relation between vitamin D deficiency and puberty in obese Spanish children, along with the possible interrelation between vitamin D status and degree of insulin resistance. Methods: A cross-sectional study was carried out, in which clinical and biochemical data were gathered from 120 obese and 50 normal weight children between January 2011 and January 2013.

Results: Mean vitamin D levels were 19.5 and $31.6 \mathrm{ng} / \mathrm{mL}$ in obese pubertal and obese prepubertal children, respectively. About $75 \%$ of the obese pubertal subjects and $46 \%$ of the obese prepubertal subjects had vitamin D deficiency. Vitamin D levels were significantly lower in pubescent subjects compared with pre-pubescent subjects in summer, fall, and winter. There was no apparent relation between vitamin D levels and homeostasis model assessment index for insulin resistence (expressed in standard deviation score for sex and Tanner stage) in either puberty or pre-puberty. Conclusion: Puberty may be a risk factor for the vitamin D deficiency commonly found in the obese child population. This deficiency is not associated with higher insulin resistance in obese pubertal children compared with obese prepubertal children.
\end{abstract}

*Corresponding author: Professor Leandro Soriano-Guillén, MD, PhD, Instituto de Investigación Sanitaria-Fundación Jiménez Díaz, Division of Pediatric Endocrinology, Department of Pediatrics, Universidad Autónoma de Madrid, Avda Reyes Católicos n 228040 Madrid, Spain, Phone: +34 915504920,

E-mail: leansor4@hotmail.com; Isoriano@fjd.es

Sonsoles Gutiérrez Medina and Adela Rovira: Instituto de Investigación Sanitaria-Fundación Jiménez Díaz, Department of Endocrinology and Nutrition, Universidad Autónoma de Madrid, Spain Teresa Gavela-Pérez, María Nieves Domínguez-Garrido and Elisa Gutiérrez-Moreno: Department of Pediatrics, Instituto de Investigación Sanitaria-Fundación Jiménez Díaz., Universidad Autónoma de Madrid, Spain

Carmen Garcés: Lipids Unit, Instituto de Investigación SanitariaFundación Jiménez Díaz, Universidad Autónoma de Madrid, Spain
Keywords: Childhood obesity; insulin resistance; puberty; vitamin D.

DOI 10.1515/jpem-2014-0033

Received January 23, 2014; accepted June 24, 2014; previously published online August 5, 2014

\section{Introduction}

In recent years, studies have found a high prevalence of vitamin D deficiency in the general population. Vitamin D has been shown to affect extraskeletal health, suggesting that it plays a role in the prevention of autoimmune and vascular diseases as well as cancer. For these reasons, there has been an increased interest in investigating the role of vitamin $\mathrm{D}$ in a healthy body, and the long-term effects of vitamin D deficiency (1-3).

Vitamin D deficiency also affects children and adolescents, especially those who are obese. Our team has demonstrated a $58 \%$ prevalence of vitamin D deficiency among obese children and adolescents. Furthermore, independently of the season, obese children showed significantly lower vitamin D levels compared with normalweight children (4).

To date, the pathogenesis of vitamin D deficiency has been attributed to various factors, including adiposity level, race, season of the year, geographical area, level of sun exposure, and dietary intake (5). The fact that vitamin $\mathrm{D}$ deficiency is more frequent in adolescents than in prepubertal children $(5,6)$ suggests that puberty may be involved in the deficiency. However, there are few data in the literature regarding the influence of puberty on the vitamin D status of obese children and adolescents; moreover, the possible correlation between vitamin D status and insulin resistance requires further clarification (6).

For these reasons, we hypothesized that obese pubertal children would exhibit greater vitamin D deficiency than prepubertal children. To test this hypothesis, we analyzed the relationship between vitamin D deficiency and puberty 
in obese Spanish children, and sought to determine whether the deficiency had an impact on insulin resistance.

\section{Materials and methods}

\section{Study design}

A cross-sectional study of the prevalence of vitamin D deficiency was performed in the Pediatrics Department of Fundación Jiménez Díaz between January 2011 and January 2013.

\section{Sample size calculation}

Sample size was calculated with Ene 2.0 program. A minimum of 96 obese children and adolescents were required for an estimated $50 \%$ prevalence of vitamin D deficiency among obese children $(7,8)$, with a $10 \%$ accuracy $(\omega)$ and a $95 \%$ confidence interval as previously reported (4).

\section{Subjects}

The subjects included obese children and adolescents, with obesity defined as a body mass index (BMI) above the 97th percentile for individuals of the same age and sex (9). We also included a lean control group with BMI between the 10th and 85th percentiles. Patients with an existing medical condition and those using chronic medication were excluded.

\section{Study variables}

The sex, age, and race of all subjects were recorded. In addition, Tanner staging was performed $(10,11)$, classifying Tanner Stage I as prepubertal and Stages II to V as pubertal. Subjects were weighed $(\mathrm{kg})$ to the nearest $0.1 \mathrm{~kg}$ using a Seca ${ }^{\circledR}$ electronic scale. Height $(\mathrm{cm})$ was measured with a Harpender ${ }^{\circledR}$ stadiometer while each subject was standing. The minimal abdominal circumference between the xiphoid process and iliac crest was measured to determine the waist circumference. Given that waist circumference changed with age, the waiststandard deviation score (SDS) was also calculated for both genders (12). Blood pressure was measured in seated subjects with a Dinamap Procare Monitor. The average of the available measurements obtained from a single visit (up to three) was used for analysis. Systolic blood pressure (SBP) and diastolic blood pressure (DBP) were also converted into age- and sex-specific percentiles, which were converted to Z scores (13). BMI was calculated by applying the formula [weight $(\mathrm{kg}) /$ height $\left.(\mathrm{m})^{2}\right]$ and expressed in both absolute values and in SDS for age and sex (9). After the first visit and following a 12-h fast, a blood sample was taken to determine $25-\mathrm{OH}$ vitamin D (lean control group and obese children) and insulin levels (obese children).

Though not an accepted standard, the categories used to classify patients according to their $25-\mathrm{OH}$ vitamin $\mathrm{D}$ plasma levels were as follows: deficient for patients with levels $<20 \mathrm{ng} / \mathrm{mL}(<50 \mathrm{nmol} / \mathrm{L})$, insufficient for levels of at least 20 but $<30 \mathrm{ng} / \mathrm{mL}(50-75 \mathrm{nmol} / \mathrm{L})$, and normal for levels $\geq 30 \mathrm{ng} / \mathrm{mL}$ ( $\geq 75 \mathrm{nmol} / \mathrm{L}$ ) (1).

We calculated the homeostasis model assessment (HOMA) index of insulin resistance as an absolute value and with SDS for sex and Tanner stage, which was calculated using reference values taken from the Spanish population (14).

\section{Biochemical measurements}

Levels of 25-OH vitamin D and insulin were determinated by chemiluminescence.

\section{Statistical analysis}

The data for the variables were expressed as mean values with the corresponding 95\% confidence interval (95\% CI). The KolmogorovSmirnov test was used to ascertain the normal distribution of all the included variables. Student's t-test was used to analyze the quantitative variables that had a normal distribution. A non-parametric Mann-Whitney U-test was used to analyze the quantitative variables that did not have a normal distribution. The $\chi^{2}$-test was used to compare qualitative variables. Statistical analyses were performed using Statview (1998).

This study was approved by the Ethics and Clinical Trials Committee of the Fundación Jimenez Díaz, Institute for Biomedical Research. Informed consent was obtained from all the subjects' patients or their guardians.

\section{Results}

\section{Obese group}

Data were collected from 120 obese children between the ages of 6 and 17 years. The clinical and biochemical data for both pubertal and prepubertal obese children are shown in Table 1 . The vitamin D deficiency rate was $75 \%$ in the pubertal group and $46 \%$ in the prepubertal group. Vitamin D levels were significantly lower in pubertal obese subjects compared with their prepubertal counterparts (Table 1).

To control for seasonal influence, vitamin D levels were analyzed in the spring, summer, fall, and winter. By following this procedure, we observed that obese pubertal children showed significantly lower vitamin D levels in the summer, fall, and winter months compared with prepubertal children (Figure 1). However, this difference was not observed in the spring. The highest and lowest levels of vitamin D were found in the summer and in the winter, respectively. No difference was observed in vitamin $\mathrm{D}$ levels between female and male children (Table 1). 
Table 1 Clinical and biochemical characteristics of obese children.

\begin{tabular}{lrrr}
\hline & $\begin{array}{r}\text { Prepubertal group } \\
\mathrm{n}=61\end{array}$ & $\begin{array}{r}\text { Pubertal group } \\
\mathrm{n}=59\end{array}$ & $\begin{array}{r}\mathrm{p} \text { (prepubertal } \\
\text { vs. pubertal) }\end{array}$ \\
\hline Age, years & $9.1(8.5-9.7)$ & $13.5(13-14)$ & $<0.01$ \\
Male/female, \% & $67.2 / 32.8$ & $45.7 / 54.3$ & $\mathrm{~ns}$ \\
BMI SDS & $2.9(2.7-3.1)$ & $2.9(2.7-3.1)$ & $\mathrm{ns}$ \\
Waist circumference SDS & $2.6(2.4-2.8)$ & $2.5(2.3-2.7)$ & $\mathrm{ns}$ \\
HOMA SDS & $3.8(3.1-4.5)$ & $2.7(1.9-3.5)$ & $\mathrm{ns}$ \\
25-OH Vitamin D, ng/mL & & \\
& $21.7(19.1-24.3)$ & $16.8(14.5-19.1)$ & $<0.01$ \\
Male & $22.1(18.8-25.3)$ & $15.2(12.3-18.1)$ & $<0.01$ \\
Female & $19.3(15.2-23.4)$ & $16.7(13.4-20)$ & $\mathrm{ns}$ \\
p (male vs. female) & $\mathrm{ns}$ & $\mathrm{ns}$ & $(\mathrm{p}=0.06)$ \\
\hline
\end{tabular}

ns, not significant.

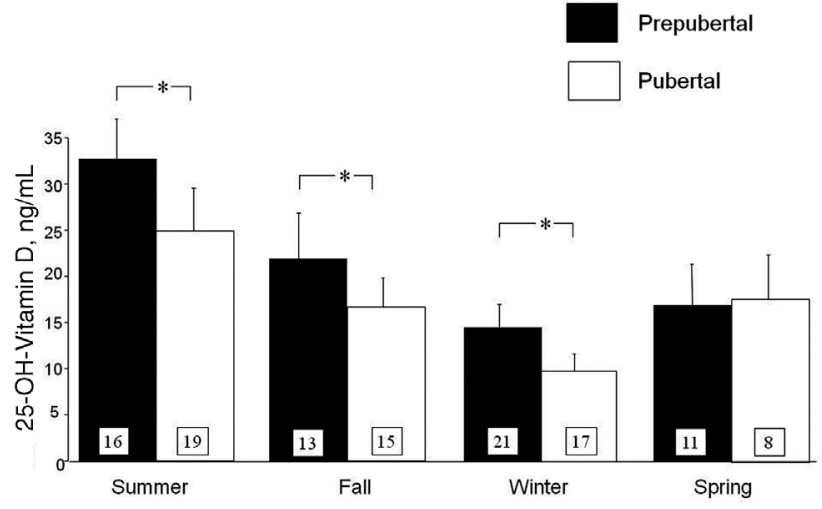

Figure 1 Comparison of vitamin D levels between prepubertal and pubertal obese children by season.

On the one hand, no significant differences were found by evaluating mean HOMA SDS in obese pubertal and prepubertal children (Table 1). On the other hand, HOMA SDS levels in all obese children were significantly lower in the summer than in the spring and in the fall, although no such difference was found in the winter (Figure 2). No significant differences were found between the other seasons. We also compared HOMA SDS for prepubertal and pubertal children in each season, and did not find significant differences: 3.7 (2.1-4.3) vs. 3.4 (1.4-5.4) in fall, 3. 2 (2.2-4.4) vs. $3.3(1.3-5.3)$ in winter, $2.7(1.7-3.7)$ vs. $1.6(0.9-2.3)$ in summer, and 2.7 (1.7-3.7) vs. $1.6(0.9-2.3)$ in spring.

Obese prepubertal children with vitamin D deficiency $(<20 \mathrm{ng} / \mathrm{mL})$ showed significantly higher HOMA SDS levels than obese prepubertal children with normal vitamin D status $(>20 \mathrm{ng} / \mathrm{mL}): 4.4(3.4-5.4)$ vs. $2.9(2-3.8)(\mathrm{p}<0.05)$. However, obese pubertal children did not have significantly different HOMA SDS levels when compared according to their degree of vitamin D deficiency: 2.7 (1.6-3.8) vs. 1.4 (0.7-2.1).

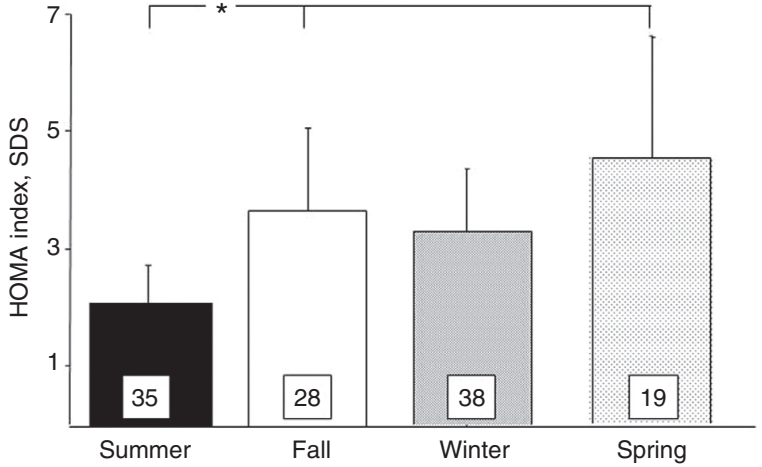

Figure 2 Comparison of HOMA SDS in obese children by season.

Finally, we conducted univariate analysis on vitamin D levels and HOMA SDS. We found no significant correlation either by analyzing the data as a whole or by dividing the data into prepubertal and pubertal subjects.

\section{Lean control group}

Data were collected from 50 children (26 females and 24 males) with a mean age of 10.44 years (9.61-11.27) and a mean BMI Z-score of -0.38 ( -0.6 to -0.16$)$. Among the subjects, 35 children were prepubertal (17 males and 18 females). In the prepubertal lean control group, there was a prevalence of vitamin D deficiency of $11.4 \%(n=4)$, of vitamin D insufficiency of $22.8 \%(\mathrm{n}=8)$, and a prevalence of normal values of vitamin $\mathrm{D}$ of $65.8 \%(\mathrm{n}=23)$. In the pubertal lean control group consisting of 15 children (7 males and 8 females), there was a prevalence of vitamin D deficiency of $6.6 \%(n=1)$, of vitamin D insufficiency of $40 \%(n=6)$, and a prevalence of normal values of vitamin D of $53.4 \%(n=8)$. 
Due to the reduced sample size of the lean control group, we decided to analyze data in two groups: autumnwinter and spring-summer. In autumn-winter, the median values of vitamin D were significantly lower in the prepubertal obese group $(n=37)$ than in the prepubertal lean control group ( $\mathrm{n}=17): 17 \mathrm{ng} / \mathrm{mL}(14.6-19.4)$ vs. $31.2 \mathrm{ng} / \mathrm{mL}$ (27-35.4). We also found significantly lower levels among pubertal obese children $(n=33)$ than in the pubertal control group ( $\mathrm{n}=8): 12.9 \mathrm{ng} / \mathrm{mL}(11-14.8)$ vs. 27.3 (20.833.8). When we compared the prepubertal and pubertal control groups, we did not find differences in vitamin D levels: $31.1 \mathrm{ng} / \mathrm{mL}$ (26.4-35.8) vs. $25.1 \mathrm{ng} / \mathrm{mL}$ (19.5-30.7).

In spring to summer, the median values of vitamin $\mathrm{D}$ were significantly lower in the prepubertal obese group $(n=28)$ than in the prepubertal lean control group $(n=18)$ : $25.8 \mathrm{ng} / \mathrm{mL}$ (21.5-30.1) vs. $34.2 \mathrm{ng} / \mathrm{mL}$ (29.4-39.2). We also found significantly lower levels among pubertal obese children $(\mathrm{n}=22)$ than in the pubertal control group $(\mathrm{n}=7)$ : $22.3 \mathrm{ng} / \mathrm{mL}$ (18.4-26.2) vs. $32.7 \mathrm{ng} / \mathrm{mL}$ (29.9-35.5). When we compared the prepubertal and pubertal control group, we did not find differences in vitamin D levels: $34.3 \mathrm{ng} / \mathrm{mL}$ (29.4-39.2) vs. $32.7 \mathrm{ng} / \mathrm{mL}$ (29.9-35.5).

\section{Pubertal stage}

Finally, we analyzed the mean vitamin D status according to the pubertal stage in the obese group and in the lean control group (Table 2) without distinction of the season of the year. We found differences in vitamin D levels in Tanner II and III-IV with regards to Tanner Stage I in the obese group. We did not find differences in vitamin D levels among the different stages in the lean control group.

\section{Discussion}

To the best of our knowledge, no previous studies conducted in different seasons of the year have analyzed the influence of puberty on vitamin D levels in obese Spanish children, and the possible connection between puberty and insulin resistance. In this study, we observed a higher prevalence of vitamin D deficiency in obese pubertal children than in obese prepubertal children.

Adolescence is a critical stage for growth, development, and bone formation. Thus, vitamin $\mathrm{D}$ requirements increase during puberty. Therefore, a vitamin deficiency during this period could affect both calcium absorption and bone formation $(15,16)$.

Numerous studies aimed to evaluate the prevalence of vitamin D in different populations. Vitamin D deficiency was more frequent in adolescents than in prepubertal children $(17,18)$, as seen in nationwide studies in Great Britain, the USA, and New Zealand. In childhood, the prevalence of vitamin D deficiency increases at older ages, and the risk of presenting this deficiency is highest during adolescence. A study conducted in Great Britain showed that $7 \%$ of British children between 1.5 and 10 years of age had 25-OH vitamin D levels of lower than $10 \mathrm{ng} / \mathrm{mL}$, while $16 \%$ of adolescents between 11 and 18 years of age showed a deficiency at some point during the year (these figures doubled when the study was conducted in winter) (19). In other European countries (20), the USA (21), New Zealand (18) and Lebanon (22), studies showed high rates of vitamin D deficiency in adolescents (46\%-92\%), especially during winter months.

These results are consistent with the data available on normal-weight adolescents. Thus, the risk of vitamin $D$ deficiency was proven to be higher in puberty in most populations analyzed $(5,22,23)$. Due to the reduced sample size of the lean control group in our study, we cannot extrapolate results, but it seems that there is a trend toward higher vitamin D deficiency and insufficiency among pubertal children.

In obese children, this increased risk of vitamin D deficiency during puberty does not seem to be related to differences in indirect parameters of adiposity, which include BMI SDS and waist SDS. Additionally, the

Table 2 25-OH-Vitamin D levels according to the pubertal stage in obese and lean control group.

\begin{tabular}{|c|c|c|c|c|c|c|}
\hline \multirow{2}{*}{$\begin{array}{l}\text { Pubertal } \\
\text { stage (Tanner) }\end{array}$} & \multicolumn{2}{|r|}{ Obese group } & \multirow[t]{2}{*}{ p-Value } & \multicolumn{2}{|r|}{ Control group } & \multirow[t]{2}{*}{ p-Value } \\
\hline & $\mathbf{n}$ & 25-OH-Vitamin D & & $\mathbf{n}$ & 25-OH-Vitamin D & \\
\hline I & 59 & $21.8(19.2-24.4)$ & & 35 & $33.1(29.7-36.5)$ & \\
\hline II & 12 & $15.5(9.5-21.5)$ & a & 3 & $33.2(31.2-35.2)$ & ns \\
\hline III, IV & 33 & $16.4(13.7-19.1)$ & $\mathrm{b}$ & 8 & $25.9(20.0-31.8)$ & ns \\
\hline V & 16 & $20.6(15.6-25.6)$ & ns & 4 & $28.7(23.0-34.4)$ & ns \\
\hline
\end{tabular}

Comparison between Tanner stages of each group (lean control and obese). ${ }^{a} p<0.05$ between Tanner II and Tanner I, ${ }^{b} p<0.05$ between Tanner III-IV and Tanner I, ns, not significant. 
difference between pubertal and prepubertal obese children was measurable during most seasons, although this difference was not as evident in spring, probably due to the smaller sample size.

The reasons why vitamin D deficiency is higher in obese children during puberty are unknown. Our study is descriptive, and as such, it is not meant to provide an etiology for this deficiency. However, like other authors (6), we suspect that the lower levels of vitamin D observed in obese pubertal children are linked to decreased sun exposure resulting from a sedentary lifestyle. We also suspect that vitamin $\mathrm{D}$ intake in both obese and non-obese adolescents is lower than in prepubertal children (24). In conclusion, we believe that the combination of limited sun exposure, lower daily intake of milk and other vitamin D-rich foods, coupled with the increased demand of vitamin D due to growth and bone remodeling, explains the increased vitamin D deficiency observed in obese adolescents.

In recent years, the relationship between vitamin $\mathrm{D}$ and glucose metabolism has been widely analyzed, although the results have been conflicting $(4,6,8,25$, 26). In this study, we observed that vitamin $D$ status and HOMA SDS differed between obese subjects during prepuberty and puberty. Surprisingly, the difference observed in the degree of insulin resistance correlated with the degree of vitamin D deficiency in obese prepubertal children was not found in obese pubertal children. Furthermore, the univariate analysis of HOMA SDS and vitamin D levels did not show a significant relationship between the two. These data lead us to believe that the higher rate of vitamin $\mathrm{D}$ deficiency in obese adolescents is not related to a higher degree of insulin resistance. Unlike vitamin D levels, HOMA index does not seem to undergo seasonal variability in obese children (4).

Our study has several limitations, such as its crosssectional nature, the absence of a nutritional survey, and the absence of data about exercise, sun exposure, and body composition. In addition, we did not assess parathyroid hormone (PTH), alkaline phosphatase, and calcium and phosphorus levels. Finally, due to the reduced sample size, we could not compare vitamin D levels among the different Tanner stages in the four seasons of the year and, for that reason, we compared prepubertal and pubertal obese children during the entire year.

In conclusion, puberty is an additional risk factor for vitamin D deficiency in obese children. On the one hand, this increased risk, together with the key role of adolescence in bone formation, makes it important to monitor vitamin D levels in obese pubertal children. On the other hand, it seems that the more acute deficiency observed in obese pubertal children is not related to a higher degree of insulin resistance, at least not directly. However, further longitudinal studies are required to evaluate the influence of puberty on vitamin D levels and its possible relation to glucose metabolism. Such studies will be necessary in order to design and establish new strategies for prevention and supplementation.

\section{Conflict of interest statement}

Disclosure statement: The authors have no conflicts of interest to disclose.

\section{References}

1. Holick MF. Vitamin D deficiency. N Engl J Med 2007;357:266-81.

2. DeLuca HF. Evolution of our understanding of vitamin D. Nutr Rev 2008;66:S73-87.

3. Rosen CJ, Adams JS, Bikle DD, Black DM, Demay MB, et al. The nonskeletal effects of vitamin D: an Endocrine Society scientific statement. Endocr Rev 2012;33:456-92.

4. Gutiérrez-Medina S, Gavela-Pérez T, Domínguez-Garrido MN, Blanco-Rodríguez M, Garcés C, et al. High prevalence of vitamin $D$ deficiency among Spanish obese children and adolescents. An Pediatr (Barc) 2014;80:229-35.

5. Tolppanen A-M, Fraser A, Fraser WD, Lawlor DA. Risk factors for variation in 25-hydroxyvitamin D3 and D2 concentrations and vitamin D deficiency in children. J Clin Endocrinol Metab 2012;97:1202-10.

6. Buyukinan M, Ozen S, Kokkun S, Saz EU. The relation of vitamin $D$ deficiency with puberty and insulin resistance in obese children and adolescents. J Pediatr Endocrinol Metab 2012;25:83-7.

7. Smotkin-Tangorra M, Purushothaman R, Gupta A, Nejati $\mathrm{G}$, Anhalt $\mathrm{H}$, et al. Prevalence of vitamin D insufficiency in obese children and adolescents. J Pediatr Endocrinol Metab 2007;20:817-23.

8. Olson ML, Maalouf NM, Oden JD, White PC, Hutchison MR. Vitamin D deficiency in obese children and its relationship to glucose homeostasis. J Clin Endocrinol Metab 2011;97:279-85.

9. Carrascosa Lezcano A, Fernández García JM, Fernández Ramos C, Ferrández Longás A, López-Siguero JP, et al. Spanish crosssectional growth study 2008. Part II. Height, weight and body mass index values from birth to adulthood. An Pediatría (Barc) 2008;68:552-69.

10. Marshall WA, Tanner JM. Variations in pattern of pubertal changes in girls. Arch Dis Child 1969;44:291-303.

11. Marshall WA, Tanner JM. Variations in the pattern of pubertal changes in boys. Arch Dis Child 1970;45:13-23.

12. Fernández JR, Redden DT, Pietrobelli A, Allison DB. Waist circumference percentiles in nationally representative samples of African-American, European-American, and Mexican-American children and adolescents. J Pediatr 2004;145:439-44.

13. Adolescents NHBPEPWG on HBP in C and the fourth report on the diagnosis, evaluation, and treatment of high blood pressure in children and adolescents. Pediatrics 2004;114(Supplement 2):555-76. 
14. García Cuartero B, García Lacalle C, Jiménez Lobo C, González Vergaz A, Calvo Rey C, et al. The HOMA and QUICKI indexes, and insulin and C-peptide levels in healthy children. Cut off points to identify metabolic syndrome in healthy children. An Pediatr (Barc) 2007;66:481-90.

15. Cashman KD. Vitamin D in childhood and adolescence. Postgrad Med J 2007;83:230-5.

16. Stoffman N, Gordon CM. Vitamin D and adolescents: what do we know? Curr Opin Pediatr 2009;21:465-71.

17. Looker AC, Dawson-Hughes B, Calvo MS, Gunter EW, Sahyoun NR. Serum 25-hydroxyvitamin D status of adolescents and adults in two seasonal subpopulations from NHANES III. Bone 2002;30:771-7.

18. Rockell JE, Green TJ, Skeaff CM, Whiting SJ, Taylor RW, et al. Season and ethnicity are determinants of serum 25-hydroxyvitamin D concentrations in New Zealand children aged 5-14 y. J Nutr 2005;135:2602-8.

19. Gregory J, Lowe S, Bates CJ. National Diet and Nutrition Survey: Young People in Britain aged 4 years to 18 years. Volume I: Report of the diet and nutrition survey. London: The Stationery Office, 2000.

20. Hill TR, Cotter AA, Mitchell S, Boreham CA, Dubitzky W, et al. Vitamin $D$ status and its determinants in adolescents from the Northern Ireland Young Hearts 2000 cohort. Br J Nutr 2008;99:1061-7.

21. Gordon CM, DePeter KC, Feldman HA, Grace E, Emans SJ. Prevalence of vitamin D deficiency among healthy adolescents. Arch Pediatr Adolesc Med 2004;158531-7.

22. El-Hajj Fuleihan G, Nabulsi M, Choucair M, Salamoun M, Hajj Shahine C, et al. Hypovitaminosis D in healthy schoolchildren. Pediatrics 2001;107:E53.

23. Ginty F, Cavadini C, Michaud P-A, Burckhardt P, Baumgartner $M$, et al. Effects of usual nutrient intake and vitamin D status on markers of bone turnover in Swiss adolescents. Eur J Clin Nutr 2004;58:1257-65.

24. Salamoun MM, Kizirian AS, Tannous RI, Nabulsi MM, Choucair MK, et al. Low calcium and vitamin D intake in healthy children and adolescents and their correlates. Eur J Clin Nutr 2005;59:177-84.

25. Mezza T, Muscogiuri G, Sorice GP, Prioletta A, Salomone E, et al. vitamin $D$ deficiency: a new risk factor for type 2 diabetes. Ann Nutr Metab 2012;61:337-48.

26. De Las Heras J, Rajakumar K, Lee S, Bacha F, Holick MF, et al. 25 -hydroxyvitamin $D$ in obese youth across the spectrum of glucose tolerance from normal to prediabetes to type 2 diabetes. Diabetes Care 2013;36:2048-53. 